\title{
PRÁCTICAS Y ACTIVIDADES RELIGIOSAS EN LOS COLEGIOS PRIVADOS DEL PAÍS VASCO DURANTE EL SIGLO XX*
}

\section{Religious practices and activities in the private schools in the Basque Country during the Twentieth Century}

\section{Paulí Dávila Balsera, ${ }^{\S}$ Luis María Naya Garmendia ${ }^{\delta}$ e Hilario Murua Cartón ${ }^{\varphi}$}

Fecha de recepción: 10/12/2015 • Fecha de aceptación: 21/01/2016

Resumen: La presencia de escuelas y colegios regidos por órdenes y congregaciones religiosas en el País Vasco, a lo largo del siglo Xx, es un fenómeno conocido. Sin embargo, es menos conocida la realización de actividades y prácticas religiosas en dichos centros. El objetivo de esta colaboración es analizar esta situación, atendiendo a dos ámbitos: 1) las actividades estrictamente religiosas, y 2) las actividades religiosas extraescolares. Las primeras se realizaban dentro de la escuela (actos litúrgicos, misas, rosarios, etc.). Se trataba de un ritual por el cual el alumnado podía vivir espiritualmente las enseñanzas religiosas vinculadas con el catecismo, la enseñanza de la religión, el evangelio o la historia sagrada. Las actividades religiosas extraescolares estaban vinculadas a asociaciones de carácter religioso e iban encaminadas a las acciones de apostolado: eucaristía o devoción mariana. Muchas de esas actividades servían para reclutar vocaciones religiosas o involucrar a la juventud en la Acción Católica. En la década de los

\footnotetext{
* Este artículo es resultado de un proyecto de investigación financiado por el Ministerio de Economía y Competitividad, proyecto número EDU2013-44129-P. Los autores son miembros del Grupo de Estudios Históricos y Comparados en Educación - Garaian, reconocido por el Gobierno Vasco con el número IT 911-16 y de la Unidad de Formación e Investigación «Educación, Cultura y Sociedad (UFI 11/54)» de la Universidad del País Vasco/Euskal Herriko Unibertsitatea UPV/EHU. Agradecemos a Alain Houry, archivero de los Archives Lassalliennes de Lyon, su colaboración para el acceso a la documentación consultada para la redacción de este artículo.

$\S$ Departamento de Teoría e Historia de la Educación. Universidad del País Vasco/Euskal Herriko Unibertsitatea. Avda. de Tolosa, 70. 20018 Donostia-San Sebastián. España. pauli.davila@ehu.eus ¿ Departamento de Teoría e Historia de la Educación. Universidad del País Vasco/Euskal Herriko Unibertsitatea. Avda. de Tolosa, 70. 20018 Donostia-San Sebastián. España. luisma.naya@ehu.eus

Departamento de Teoría e Historia de la Educación. Universidad del País Vasco/Euskal Herriko Unibertsitatea. Avda. de Tolosa, 70. 20018 Donostia-San Sebastián. España. hilario.murua@ehu.eus
}

Cómo citar este artículo: Dávila Balsera, Paulí; Naya Garmendía, Luis M. y Murua Cartón, Hilario. «Prácticas y actividades religiosas en los colegios privados del País Vasco durante el siglo XX», Historia y Memoria de la Educación, 4 (2016): 141-175. 
setenta del siglo xx estas actividades disminuirán o cambiarán de signo. Para ejemplificar este proceso, que estaba generalizado en la mayoría de escuelas, nos hemos centrado en los colegios y escuelas de La Salle en el País Vasco. La metodología histórica aplicada está en función de las diversas fuentes analizadas (fotografías, documentación de archivo, memorias escolares, etc.). El corpus documental procede de los archivos y museos de La Salle. Se puede concluir que durante el Franquismo se acrecienta la realización de las actividades señaladas, en un contexto donde la enseñanza de la religión tenía un papel relevante. Este tipo de actividades servían para afianzar la fe y arraigar la religiosidad entre los alumnos.

Palabras clave: La Salle. País Vasco. Actividades religiosas. Congregaciones Religiosas. Acción Católica.

Abstract: The presence of schools ruled by religious orders and congregations in the Basque Country throughout the Twentieth century is a known phenomenon. What is less known are the kinds of activities religious practices carried out in these schools. The objective of this collaboration is to analyse this situation, with a focus on two aspects: 1) the religious activities and, 2) the extracurricular religious activities. The first of these were carried out within the schools (liturgical acts, masses, rosaries, etc.). They were the rituals by which the student body could live spiritually through the religious teaching linked to catechism, religious education, the gospel or sacred history. The extracurricular activities were related to religious associations which were used for carrying out certain apostolic actions. Many of these activities served to recruit religious vocations or to involve the youth in Catholic Action. In the 1970s, these activities diminished and evolved. As an example of this process, which was extended to the majority of the schools, we have focused on the De La Salle schools in the Basque Country. A historical methodology has been applied to the diverse sources that have been analysed (photographs, archival documentation, etc.). The documentary corpus comes from the files and museums of De La Salle Brothers. We can conclude that during Franco's regime, under which the teaching of the Catholic religion played an important role, the practice of these activities increased.

Keywords: De La Salle. Basque Country. Religious Activities. Religious Congregations. Catholic Action. 


\section{INTRODUCCIÓN}

En España, durante el primer tercio del siglo xx, y debido a un conjunto de fenómenos complejos, las relaciones entre la Iglesia y el Estado atravesaron un periodo conflictivo donde, frente a la política laicista de algunos gobiernos, la acción política de la Iglesia cambiará, dejando su aislamiento tradicional, para pasar a una acción conjunta. ${ }^{1}$ La Iglesia comenzó a organizarse a partir de los Congresos Católicos y, sobre todo, de la Acción Católica que, a partir de 1903, comienza a aglutinar las fuerzas alrededor de sus prelados y de personalidades destacadas del catolicismo, como el marqués de Comillas. ${ }^{2}$ Con el transcurrir del tiempo la Acción Católica se conformará en un movimiento de defensa de la Iglesia y de una derecha católica decidida a organizar a las masas. ${ }^{3} \mathrm{El}$ primer Congreso Nacional de Educación Católica, celebrado en Madrid en 1924, fue una muestra de colaboración entre los obispos españoles secundados por todos los miembros del episcopado, las congregaciones religiosas dedicadas a la enseñanza y el clero regular. Por supuesto no faltaron a la cita ni los reyes ni el nuncio apostólico, el Sr. Tedeschini. ${ }^{4}$ El surgimiento de círculos católicos o de sindicatos de orientación católica, irá completando esta compleja organización de la Iglesia, a la que se unirá otro tipo de organizaciones, entre ellas, en 1930, la Federación de Amigos de la Enseñanza (FAE), en la que tuvo un papel importante el marianista Domingo Lázaro. ${ }^{5}$

La Segunda República, su declarado laicismo, la expulsión de los jesuitas y la ley sobre congregaciones religiosas de 1933, de escasa aplicación, además de los desmanes en contra de muchas congregaciones durante la guerra civil, supuso un periodo en el que la Iglesia vio peligrar su situación privilegiada dentro del sistema educativo. La victoria franquista

\footnotetext{
${ }^{1}$ Vicente Faubell, «Educación y órdenes y congregaciones religiosas en la España del siglo XX», Revista de Educación, 2000 (Núm. Extraordinario), 137-200.

${ }^{2}$ William James Callahan, La Iglesia católica en España (1875-2002) (Barcelona: Crítica, 2003), 100.

${ }^{3}$ Feliciano Montero, «Del movimiento católico a la Acción Católica. Continuidad y cambio», en La secularización conflictiva. España (1898-1931), ed. Julio De La Cueva y Feliciano Montero (Madrid: Biblioteca Nueva, 2007), 169-185.

${ }^{4}$ Institute des Écoles Chrétiennes, «Le premier congrès national de l'éducation catholique à Madrid», Bulletin des écoles Chrétiennes, 3, (1924): 213-220.

${ }^{5}$ Paulí Dávila y Luis M. Naya, «La enseñanza privada religiosa en España: instituciones, políticas e identidades», en Laicidade, Religiões e Educação na Europa do Sul no Século XX, ed. Joaquín Pintassilgo (Lisboa: Instituto de Educação da Universidade de Lisboa, 2013), 367-392, 381.
} 
de 1939 afianzó la presencia de las órdenes y congregaciones religiosas en la enseñanza. Además de disfrutar de una legislación favorable, con el concepto de subsidiariedad escolar del Estado con respecto a la Iglesia, aumentó la presencia del clero dentro de las escuelas, con la victoria del denominado «nacional-catolicismo». La enseñanza de valores como la patria y la religión católica, como disciplina académica, va a ser el foco alrededor del cual se organice la nueva concepción del Estado y la Iglesia en el nuevo régimen político. Este fenómeno está más o menos estudiado dentro de la historiografía sobre la enseñanza de la religión en las aulas. ${ }^{6}$ Pero, con ser importante este fenómeno, nos falta por conocer los rituales, actividades y prácticas llevados a cabo en el interior de las aulas, sobre todo en los colegios religiosos, ya que nos permitirá explicar el grado de penetración de una disciplina obligatoria y de gran peso dentro del currículum escolar. Por otra parte, las escuelas y colegios públicos se verán contagiados por las prácticas religiosas llevadas a cabo en los centros privados, que se convertirán en modelo para aquella. ${ }^{7}$ Con la Ley General de Educación de 1970 comenzará el declive de este tipo de prácticas.

\section{RELIGIOSIDAD EN EL PAÍS VASCO: DEVOCIÓN MARIANA Y EUCARISTÍA}

A la religiosidad característica del pueblo vasco y a la presencia del catolicismo en multitud de manifestaciones populares durante el siglo $\mathrm{xx}$, tenemos que sumarle la llegada de multitud de órdenes y congregaciones religiosas que consiguieron un enorme éxito con el establecimiento de escuelas y colegios. Entre las congregaciones que llegaron, La Salle logró una amplia expansión por todo el territorio. ${ }^{8}$ Este hecho se debe, entre otras causas, al exilio religioso que se inicia en 1904, debido a la política laicista y los decretos anticongregacionistas que se dictan en Francia y que excluían a las órdenes y congregaciones religiosas de la enseñanza. ${ }^{9}$ A partir de este momento, este instituto religioso creó en

\footnotetext{
${ }^{6}$ Antonio Viñao, Religión en las aulas. Una materia controvertida (Madrid: Ediciones Morata, 2014).

${ }^{7}$ Natividad Araque, «La enseñanza de la religión en el Instituto Nacional Femenino de enseñanza media "Isabel La Católica" de Madrid durante el franquismo», Historia de la Educación, 30 (2011): 221-240.

${ }^{8}$ Saturnino Gallego. Sembraron con amor. La Salle, Centenario en España (1878-1978) (San Sebastián: Conferencia de Visitadores FSC, 1978).

${ }^{9}$ Henri Bedel, FSC, «An introduction to the History of the Institute of the Brothers of the Christian Schools. 19th and 20th Century (1875-1928)», Lasallian Studies, 11 (2006): 207-239.
} 
España una red de escuelas primarias, profesionales y de secundaria de amplio reconocimiento. ${ }^{10}$ La acogida de los Hermanos de La Salle en España supuso una etapa de crecimiento de centros inesperado. Los Hermanos se distribuyeron por toda la geografía española, apreciándose la creación de importantes centros educativos, sobre todo en las provincias limítrofes con Francia, posiblemente con la idea de un retorno no muy lejano en el tiempo y aprovechando la no prohibición para establecerse en las mismas. ${ }^{11}$

En 1904 existían en España 47 comunidades (conjunto de Hermanos dedicados mayoritariamente a la docencia), formadas por 381 Hermanos, que atendían a unos 12.763 alumnos. En 1913 podemos ver que la situación ha cambiado sustancialmente, pues son ya 132 comunidades las constituidas, con 1.245 Hermanos y atendiendo a 26.026 alumnos. Por lo tanto, en 10 años el número de alumnos se duplica y el número de comunidades casi se triplica, a pesar de la situación política anticlerical de esa época en España. ${ }^{12}$ Durante este periodo la composición de estas comunidades era mayoritariamente de Hermanos franceses. Poco a poco comienza a apreciarse la incorporación de Hermanos españoles a los diferentes distritos creados, debido a las nuevas vocaciones y a la formación de Hermanos locales en los distintos noviciados creados a tal fin. Por lo tanto, se trata de un proceso de «hispanización» de las comunidades que va a tener repercusiones evidentes en la posterior evolución y asentamiento de La Salle en España. ${ }^{13}$ La vuelta de los Hermanos franceses a su país, debido a la primera guerra mundial, supuso una cierta estabilidad durante 1918 y 1938, aunque en los años de la guerra civil bajó

\footnotetext{
${ }^{10}$ Pedro Gil (1997), «Hermanos de las Escuelas Cristianas, lasalianos», en Historia de la acción educadora de la Iglesia en España. Edad Contemporánea, ed. Bernabé Bartolomé (Madrid: Biblioteca de Autores Cristianos, 1997), 437. También se pueden consultar los anexos de la obra de Gallego, Sembraron con amor.

11 Jean Marc Delaunay, «Exilio o refugio en España (veinticinco años después)», Anuario de Historia de la Iglesia, XIV (2005): 153-164, y Paulí Dávila «Las órdenes y congregaciones religiosas francesas y su impacto sobre la educación en España. Siglos XIX y XX», en Francia en la educación de la España contemporánea (1808-2008), ed José M. Hernández (Salamanca, Ediciones de la Universidad de Salamanca, 2011), 101-160.

12 Teódulo García Tejedor, La polémica sobre la secularización de la enseñanza en España (1902-1914) (Madrid: Fundación Santa Maria, 1985); Faubell, «Educación y órdenes»; Ivonne Turin, La educación y la escuela en España de 1874 a 1902 (Madrid: Aguilar, 1967); Frances Lannon, Privilegio, persecución y profecía. La Iglesia Católica en España 1875-1975 (Madrid: Alianza Editorial, 1987), o Ana Yetano, La enseñanza religiosa en la España de la Restauración (1900-1920) (Barcelona: Anthropos, 1988).

13 Dávila «Las órdenes y congregaciones».
} 
sustancialmente el número de comunidades, de Hermanos y de alumnos. Tras la guerra civil podemos afirmar que los institutos religiosos viven una época dorada, donde no dejarán de crecer en número de centros, de alumnos y de profesores. En el País Vasco fue donde su presencia fue más notable con casi veinte centros establecidos. ${ }^{14}$

En este contexto de proliferación de centros la religiosidad aumentó. El periodo de posguerra es significativo para que se pusiesen de relieve las manifestaciones públicas y privadas de esta religiosidad, sobre todo en el ámbito escolar, que será el espacio privilegiado para orientar voluntades. Así un ejemplo de esta situación se puede apreciar en el colegio de San Marcial de Irún (Gipuzkoa) desde 1939, donde el Hermano Visitador recomendaba fomentar

la piedad en los alumnos y háblenles de la vocación religiosa y procurad que los Hermanos ofrezcan escapularios, medallas y rosarios a los alumnos, y que éstos recen bien, que se confiesen y que comulguen con fervor. En una palabra, procuren formar y educar bien. ${ }^{15}$

La consigna era bien simple, pero en su interior se escondía todo un vademécum de prácticas y actividades de orden religioso. Si bien estos consejos servían para orientar la actividad escolar, la manifestación pública de esa religiosidad era una práctica muy extendida. En este sentido, dos acontecimientos marcan el transcurso de los años cuarenta y cincuenta: El Congreso Eucarístico de 1945 y la celebración del Año Mariano en 1954. Ambos están relacionados con dos actividades que están muy presentes en los colegios religiosos, la práctica de la eucaristía como sacramento y la devoción mariana, sustentada en diferentes asociaciones que surgen en los colegios.

Por lo que respecta al Congreso Eucarístico regional de 1945, hay que tener presente la tradición de la devoción a la eucaristía que arranca desde el siglo XIX. El amor a Jesucristo se materializa a través de la necesidad de la Santa Comunión que es el «acto esencial de la devoción a la

\footnotetext{
${ }_{14}$ Paulí Dávila, Luis M. Naya e Hilario Murua, Bajo el signo de la educación. 100 años de La Salle en Gipuzkoa (Donostia: Distrito de Bilbao, 2009).

15 Supplément à l'Historique pour l'année 1939.
} 
eucaristía», ${ }^{16}$ sacramento cuyo apoyo evangélico está en Mateo, 26, cuando dice "coged y comed, éste es mi cuerpo». La comunión se entiende como una recuperación de las fuerzas del alma. Toda esta devoción necesitaba una preparación de acción de gracias y bajo estos presupuestos se explican las prácticas eucarísticas, tanto en las actividades religiosas escolares, como en los sacrificios necesarios fomentados por las asociaciones eucarísticas que trataremos posteriormente.

En el ámbito público, la celebración de congresos eucarísticos nacionales y regionales fue una práctica bastante habitual durante el franquismo. El más famoso de ellos fue el $35^{\circ}$ Congreso Eucarístico Internacional, celebrado en Barcelona, en 1952 durante el pontificado de Pío XII, con el objetivo de dar culto a la eucaristía. Además, se celebraron otros congresos eucarísticos nacionales. El primero de ellos tuvo lugar en Valencia en 1893, el segundo en Lugo en 1896, el tercero en Toledo en 1926. Esta tradición se recuperará en 1957, celebrándose en cinco ocasiones hasta 1972.

Además de estos congresos nacionales, también los hubo regionales. Entre los celebrados en el País Vasco, uno de especial relevancia fue el de Bergara de 1945. El día de su apertura, por la mañana hubo misa de comunión para unos 2.000 niños y el orden y la piedad fueron perfectos, a pesar de la fina llovizna. No se deslució del todo el acto, pero sí hubo alguna queja por parte de los Hermanos de La Salle en relación a la organización de la jornada de los congresistas,

cuando los 150 niños que se alistaron como tales con otro centenar de niñas, se dirigieron llenos de entusiasmo en cinco camiones cedidos por la Fábrica de D. Patricio y la Papelera. Hubo por la mañana en el Ensanche de Amara una Comunión General en la que participaron unos 20.000 niños. Todo esto resultó verdaderamente magnífico, aunque un tiempo algo lluvioso y alguna lentitud en la organización deslucieron un poco su esplendor. ${ }^{17}$

\footnotetext{
${ }^{16}$ Institute des Écoles Chrétiennes, Dévotion à l'Eucharistie, Circular del Superior de los Hermanos de la Escuelas Cristianas de 5 de enero de 1867 (Lembecq Lez Hall (Bélgica), Maison St. Joseph, 1867).

17 Supplément à l'Historique pour l'année 1946. Archivo de los Hermanos de La Salle del Distrito de Bilbaso, Loyola, San Sebastián (AHLSB).
} 
Otro ejemplo es el del colegio de San José de Zarautz (Gipuzkoa), que registró algunos hitos dentro de esta actividad como la asistencia de 70 alumnos al Congreso Eucarístico celebrado en Irún en 1945, o el paso en 1947 por la Diócesis de Guipúzcoa de la imagen de la Virgen de Fátima "que se destina a Rusia cuando se convierta, tocó la suerte de poseerla en esta villa, el 16 de junio. El Cabildo parroquial la recibió al mediodía, a la entrada del pueblo y la muchedumbre, en la Plaza con vítores y agitación de pañuelos» ${ }^{18}$ y acudió el colegio.

Por lo que respecta a la celebración en 1954 del Año Mariano, debemos tener e cuenta algunos antecedentes. Así la devoción a la Virgen María, tras la proclamación del dogma de la Inmaculada Concepción cien años antes, marcó un ritmo creciente, tanto en la creación de congregaciones religiosas, la mayoría de ellas dedicadas a la enseñanza y cuya identidad mariana está presente, como en la incorporación de la Virgen María al imaginario colectivo y a las prácticas educativas. ${ }^{19}$

En el ámbito educativo, y con fecha anterior a que el Bulletin de las Escuelas Cristianas de 1907 se refiriese a la devoción a la Virgen María en las escuelas, ${ }^{20}$ la circular 102 de 26 de abril de $1901^{21}$ se refiere a la misma dentro del Instituto religioso. Las menciones que hace San Juan Bautista de La Salle a la Virgen y las solicitudes de diferentes superiores del Instituto sirvieron de argumento para introducir esta práctica en las escuelas y pensionados. Con este objetivo los Hermanos de La Salle llevaron a cabo una prudente y discreta distribución de imágenes, difusión de libros, oraciones y ejemplos para impresionar favorablemente a los niños, organizando misas y triduos, etc. todo ello en colaboración con las autoridades eclesiásticas. El Bulletin de 1907 recoge un artículo sobre la devoción a la Santísima Virgen María en las escuelas cristianas a partir de la consideración de que María es la gran Educadora de la juventud, haciendo notar que ya en 1750, con la fundación del pensionado de Marsella, se organizó entre los alumnos una congregación bajo la advocación

\footnotetext{
18 Supplément à l'Historique pour l'année 1945 (AHLSB).

19 Dávila «Las órdenes y congregaciones», y Dávila y Naya «La enseñanza privada religiosa».

${ }^{20}$ Institute des Écoles Chrétiennes, «La dévotion envers la Très Sainte Vierge dans les écoles Chrétiennes», Bulletin des Écoles Chrétiennes, 3 (1907): 129-137.

${ }^{21}$ Institut des Frères des Écoles Chrétiennes, La dévotion à la Très Sainte Vierge dans notre Institut, Circular n. ${ }^{\circ} 102$ (Paris, 1901).
} 
de la Inmaculada Concepción. En posteriores capítulos de la Congregación los superiores promovieron la creación de asociaciones dedicadas a la Virgen María. Por ejemplo el Hermano Irlide insiste en una carta de enero de 1883 en la necesidad de crear este tipo de asociaciones, incluso aunque la escuela sólo cuente con dos o tres aulas. ${ }^{22}$ Estas asociaciones se van extendiendo por España, Italia, Oriente Medio, etc. Sorprende que en este mismo escrito se cite el colegio Condal de Barcelona, elogiando a la asociación de este centro por la cantidad de actividades que realizaba: catequesis a obreros e hijos de obreros, clases a obreros, visitas a presos y otras prácticas que llevan desarrollando desde principios de siglo en el centro barcelonés, al igual que otros tantos centros religiosos regidos por La Salle.

Además de esta devoción a la Virgen María en el ámbito escolar, también la legislación en la época franquista la tuvo presente. Ya en 1937, a través del Decreto 426, se dispone que «el 8 de diciembre, conmemoración de la Inmaculada Concepción de Nuestra Señora, será día de fiesta en todo el territorio nacional». ${ }^{23}$ En los años siguientes este fervor legislativo es continuo, con la autorización de sellos de correos para conmemorar el centenario de la venida de la Virgen del Pilar; declarando a la Virgen de la Merced patrona de las prisiones; la Virgen del Buen Consejo como patrona del Consejo de Estado, etc. En el ámbito escolar se produce la consagración de escuelas al Inmaculado Corazón de María, a través de una comunicación del Director de Primera Enseñanza a los inspectores de toda España, dando instrucciones de actuación a los mismos a fin de consagrar las escuelas a la Virgen. ${ }^{24}$ Sin duda, esta legislación estaba conforme con los contenidos y actuaciones de Franco donde mostraba su gratitud y devoción a la Virgen María.

Con estos antecedentes sólo faltaba conmemorar el centenario de la proclamación del Dogma de la Inmaculada Concepción por el Papa Pio IX, al convocar, a través de la encíclica Fulgens Corona, el año 1954 como Año Mariano. En España este acontecimiento no pasó desapercibido, como podemos ver por la crónica del año mariano en la archidiócesis de Toledo, donde se llevó a cabo un amplio elenco de actividades: ánge-

\footnotetext{
22 Institut des Frères des Écoles Chrétiennes, La dévotion à la Très Sainte Vierge.

${ }^{23}$ Nazario Pérez, Historia Mariana de España (Salamanca: Imprenta Kadmos, 1995), Tomo II, 957.

24 Pérez, Historia Mariana de España, II, 957.
} 
lus, sabatinas, primeros sábados de mes, novenas, procesiones, meses de mayo y octubre, peregrinaciones, María en los hogares, etc. ${ }^{25}$ La actividad del 31 de octubre congregó a más de 40.000 fieles en torno a 150 imágenes procedentes de los distritos de los arciprestazgos de la diócesis.

En las escuelas del País Vasco este evento tampoco pasó desapercibido. Así, en la escuela San José de Zestoa (Gipuzkoa), a petición de las autoridades eclesiásticas, se hizo una

fastuosa recepción a la Madre del Cielo, saliendo a las afueras de la Villa todos los alumnos y gentes del pueblo. Fue aclamada con enérgicos vítores, aplausos, bombas reales, cantos y con el rezo del Santo Rosario hasta llegar a la Parroquia. Allí recibió toda clase de muestras de afecto durante 4 días, al cabo de los cuales se despidió organizando en su honor un llamativo festejo. ${ }^{26}$

Pero de mayor relevancia fue lo ocurrido en el Colegio de los Ángeles de San Sebastián, ya que durante todo el año 1954

las clases rivalizaron en fervor y entusiasmo mariano adornando los altarcitos de la Santísima Virgen de las respectivas clases con profusión de flores y dedicando lo mejor de sus cantos y de sus rezos. Era digno de oírse el rezo diario de la oración mariana compuesta por su Santidad el Papa que pronto todo el alumnado aprendió a rezar de memoria.27

Como acto oficial mariano, patrocinado por la Congregación mariana, se celebró una peregrinación al Santuario de la Virgen de la Asunción de Azkoitia (Gipuzkoa). En el cierre del Año Mariano, el 8 de diciembre se llevaron a cabo varios actos, sobresaliendo la sesión literario-musical de la víspera y la procesión de las antorchas:

en la primera participó todo el colegio en un programa lleno de emotividad y de arte en el que se mezclaron las armonías de-

\footnotetext{
${ }^{25}$ Ayuntamiento de Toledo. Crónica del año mariano en la archidiócesis de Toledo, primada de España, con motivo del centenario de la definición del dogma de la Inmaculada (Toledo: Editorial Católica Toledana, 1954).

${ }^{26}$ Dávila, Naya y Murua, «Bajo el signo de la educación», II, 246.

27 Supplément à l'Historique pour l'année 1954 (AHSLB).
} 
leitosas, los recitales poéticos embelesadores, las disertaciones teológicas y las emociones sentidas a través del canto mariano entonado por las voces del Hermano Subdirector del Colegio. Del acto final, que fue la emocionante procesión nocturna, y la consagración recitada por el Hermano Director ante el colegio todo, nos queda un inolvidable recuerdo. Aquel rezo apropiado a María, ofreciéndole los corazones de todos mientras el aire perfumaba con el aroma del incienso quemado al rescoldo de los tesoros espirituales que ardían en holocausto y en homenaje a nuestra Reina y Señora. ${ }^{28}$

\section{ACTIVIDADES RELIGIOSAS ESCOLARES}

En este contexto de religiosidad, las prácticas y actividades religiosas en las escuelas no son más que un correlato que continúa la capacidad de penetración de la religión en el ámbito escolar, como se aprecia en los siguientes epígrafes.

En la mayoría de los centros de La Salle, como hemos podido comprobar a través de su documentación y por las memorias escolares analizadas, las actividades religiosas estuvieron presentes de forma continuada. Este fenómeno no es propio únicamente de los centros regidos por los Hermanos de las Escuelas Cristianas, sino que estaba presente en otros centros religiosos e, incluso, en la mayoría de escuelas públicas, sobre todo en el periodo comprendido entre 1939 a 1970. Este tipo de educación religiosa se puede observar también en los cuadernos escolares, donde además de las lecciones sobre el Santo Evangelio, quedan marcadas otras celebraciones dedicadas a la Virgen María. ${ }^{29}$ El conjunto de celebraciones anuales, en muchos casos, sobrepasa los más de veinte eventos, aunque no todos sean del mismo rango. En este sentido, una vez enumerados todos los días festivos que se registran en dicha documentación podemos distinguir una serie de celebraciones periódicas y otras más puntuales. Dentro de las ac-

\footnotetext{
28 Supplément à l'Historique pour l'année 1954 (AHSLB).

29 Bienvenido Martín e Isabel Ramos, La historia contada en los cuadernos escolares (Madrid: Los Libros de la Catarata, 2015), 125-126, o Ana María Badanelli y Kira Mahamud, «Cuadernos escolares: un ejemplo de la práctica de la escritura en el franquismo», en Mis primeros pasos. Alfabetización, escuela y usos cotidianos de la escritura (siglos XIX y XX), eds. Antonio Castillo y Verónica Sierra (Gijón: Ediciones Trea, 2008), 259-279.
} 
tividades periódicas también cabe distinguir entre las fiestas litúrgicas de la Iglesia (San José, Domingo de Ramos, Santo Tomás, Inmaculada, Cristo Rey, Santísima Trinidad, Sagrado Corazón, Todos los Santos, Corpus Christi, Virgen del Pilar, etc. y las fiestas patronales de cada localidad en la que estaba el centro) y otras fiestas internas de los propios centros (Beato Benildo, Beato Salomón, San Juan Bautista de La Salle, etc.). Así, en el centro de Legazpia, cuando se produjo la beatificación del Hno. Benildo los niños la oyeron por la radio, y

era esperada con vivo anhelo por todos los alumnos. Fervorosísimo novenario precede a este día señaladísimo. La víspera, a las ocho de la tarde el disparo de cohetes alborota a la vecindad. El toque de las campanas anuncia la fiesta. La capilla, primorosamente adornada. Todo está preparado para la fiesta. Alegres y risueños acuden presurosos al rayar los primeros albores del alba. Vienen exultantes de alegría a ofrendar a su santo patrono con una fervorosa comunión. ${ }^{30}$

Asimismo, dentro de esta misma categoría se puede recordar la celebración del mes de mayo como el mes de María. Esta ofrenda tenía por objeto meditar sobre los cuatro dogmas acerca de la Virgen María: su inmaculada concepción, su maternidad divina, su perpetua virginidad y su asunción a los cielos. Durante ese mes aquellos centros que tenían capilla aneja solían proceder a adornarla con flores blancas llevadas, en muchos casos, por los propios alumnos. Esta celebración, que para muchos es una especie de saludo a la primavera, fue asumida por la Iglesia como una fiesta de exaltación de la Virgen María. En algunos centros también el mes de junio se dedicaba a la veneración del Sagrado Corazón de Jesús en el cual se incluía un conjunto de reflexiones alrededor de cuestiones de la vida religiosa y también de comportamientos de la juventud.

Estas actividades no siempre suponían una ruptura del calendario escolar, sino que estaban incorporadas en el propio horario, antes del inicio de las clases propiamente dichas, excepto aquellas que coincidiesen con un día festivo. En el caso de la fiesta de San Juan Bautista de La Salle, patrón del magisterio cristiano y de la congregación, la celebración dentro del propio centro superaba las actividades religiosas, incluyendo algunas

30 Supplément à l'Historique pour l'année 1952 (AHSLB). 
de tipo lúdico o deportivo. Tan sólo como ejemplo podemos señalar la celebración del tricentenario de su nacimiento, en 1951 en Andoain, con un homenaje de los niños de Gipuzkoa a San Juan Bautista de La Salle, a la que se sumaron unos 500 niños de Bizkaia.

Cabe detectar que el mayor número de actividades religiosas se llevaban a cabo en los centros pequeños, como eran Hondarribia, Usurbil y Zestoa, donde las celebraciones superan las 25 al año. También hay que destacar otro conjunto de actividades religiosas, como eran las procesiones, algunas de las cuales recorrían las calles de la ciudad. Como ejemplo de este tipo de actividades, en el prestigioso centro de La Salle de San Sebastián, se realizaban, además de las procesiones, otro tipo de actos que muestran la piedad, el comportamiento de los niños, etc. a los que se añaden el año jubilar ignaciano y la procesión tradicional con antorchas, con motivo de la fiesta de la Purísima en 1956; centenario de nuestra señora de Lourdes en 1958; procesión del Corpus Christi; postulación del Domund; procesiones y vísperas para el Corpus y de la Inmaculada. Esta última celebrada en 1959 tuvo especial relevancia, pues

las luminarias que portaban los alumnos ofrecían un aspecto tan sorprendente como piadoso haciendo exclamar a los numerosos asistentes que parecía «un Lourdes-chiqui» en su lengua vernácula, es decir un Lourdes en pequeño. Este acto estuvo honrado con la presencia del Reverendo Hermano Visitador. ${ }^{31}$

Otras celebraciones más esporádicas se llevaron a cabo durante la década de los 60 y están relacionadas con el «día del crucifijo» que comenzó a celebrarse en 1962 en el Colegio San Luis de San Sebastián y duró hasta finales de la década. Esta celebración fue promovida ese año por la Unión de Catequistas de Jesús Crucificado y María Inmaculada

como jornada dedicada a honrar el Sto. Crucifijo. Con este fin, todos los alumnos asistieron a una ceremonia en la iglesia. El ejercicio de las Cinco llagas, alma de la Unión de Catequistas, fue fervorosamente rezado por todos. Por otra parte, esta jornada tuvo un ambiente y preparación en las clases. ${ }^{32}$

\footnotetext{
31 Supplément à l'Historique pour l'année 1959 (AHSLB).

${ }^{32}$ Crónica del Colegio San Luis de Alza-Herrera 1964.
} 
No obstante, estas fiestas, en general, se producen en un contexto de religiosidad propiciado en la escuela por los propios Hermanos, quienes seguían los consejos del Hermano Visitador referentes a mantener ideas religiosas, tanto en la pedagogía catequística como en la general y «no cansarse en inducir a los alumnos a una conveniente frecuencia de sacramentos». ${ }^{33}$

Dentro de los sacramentos el que tenía mayor realce era la Primera Comunión, como puede observarse en las memorias escolares y en la documentación. Obsérvese la narración tan colorista al referirse a ella

solícitamente preparados e instruidos por el Hermano Profesor y el Señor Párroco, el domingo de Quasimodo los inocentes corazones reciben a Jesús. Día de gala y hermosura para todos nosotros, viéndoles tan apañaditos, luciendo sus trajes de azul marino. Y para Jesús, visitando aquellos vergeles deliciosos que eran sus pechos. El soñado día dejó huella indeleble en los tiernos corazones. ${ }^{34}$

De la misma manera se expresaba otro narrador del colegio Loinaz de Beasain: «el ansiado día llegó y desde el amanecer todos formalitos se encontraban en el patio del colegio; sus mejores trajes y sus almas cándidas traslucían en sus rostros a Jesús Sacramentado, que pronto iba a ser morada de sus anhelantes corazones». ${ }^{35}$

No obstante, la alegría que suponía para los Hermanos de La Salle el poder acompañar a los niños en la Primera Comunión se veía empañada, en general, por un conflicto permanente entre los Hermanos y los cura-párrocos, quienes eran los encargados de preparar la catequesis. Este conflicto puede apreciarse en los casos de Ordizia o Beasain. Así, en el primer caso se afirma que las heridas continuaban abiertas, a pesar de que en 1951 les enviasen unos 30 niños para que hiciesen la Primera Comunión, a petición expresa de los Sacerdotes, porque en 1953, los Hermanos dicen textualmente: «el que sean los señores sacerdotes los encargados de la preparación directa de los niños a la Primera Comunión

\footnotetext{
${ }^{33}$ Los Ángeles. San Sebastián. Supplément à l'Historique pour l'année 1956 (AHSLB).

${ }^{34}$ Supplément à l'Historique pour l'année 1951 (AHSLB).

${ }^{35}$ Supplément à l'Historique pour l'année 1945 (AHSLB).
} 
es costumbre arraigada en la provincia. No obstante, no se descuidó en el colegio esta obligación moral que tenemos, aunque después sean los sacerdotes quienes se llevan la gloria ${ }^{36}$ y en 1955 vuelvan a hacer algún comentario al respecto «los encargados de la preparación directa son los sacerdotes. No obstante, no implica que los Hermanos descuidemos la preparación de estos angelitos». ${ }^{37}$

\section{ACTIVIDADES RELIGIOSAS EXTRAESCOLARES}

Si bien es en la escuela donde se localizan la mayoría de actividades religiosas, lo cierto es que también podemos registrar otro conjunto de actividades donde la escuela actúa como referencia, pero que, en realidad, tienen una proyección más extraescolar. Nos referimos a los certámenes catequéticos, los ejercicios espirituales y convivencias o la organización de asociaciones para el alumnado a fin de promover las obras de apostolado. Este tipo de actividades estaban muy extendidas en los colegios de otras órdenes o congregaciones. ${ }^{38}$ Entre estas actividades sin duda la que tiene una mayor relevancia es la organización de las diferentes asociaciones. Todas estas agrupaciones, bajo la denominación de obra de apostolado estaban encaminadas, en último término, a preparar al alumnado a una acción más o menos involucrada en los principios de la Acción Católica, cuya relevancia en esta época es incuestionable. ${ }^{39}$

\section{Certámenes catequéticos}

Las obras de catequesis voluntaria son una de las formas de apostolado que se comenzaron a llevar a cabo a finales del siglo xix. Sus objetivos eran la evangelización y, muy especialmente, la preparación para la Primera Comunión de los niños. En París se fundaron un poco después de los decretos laicistas de 1880 y fueron muy bien acogidas

\footnotetext{
36 Supplément à l'Historique pour l'année 1951 (AHSLB).

37 Supplément à l'Historique pour l'année 1955 (AHSLB).

${ }^{38}$ Enrique Llull Martí, Jesuitas y pedagogía. El Colegio San José en la Valencia de los años 20 (Madrid: Universidad Pontificia Comillas de Madrid), 551.

${ }^{39}$ Feliciano Montero, «Los movimientos juveniles de Acción Católica: de la militancia apostólica al compromiso político», en De la dictadura a la democracia: la acción de los cristianos en España (19391975), eds. José María Castells José Hurtado, Josep María Margenat (Bilbao: Desclée de Brower, 2005), 263-293.
} 
por el Papa Pío X, apodado el Papa del catecismo. Uno de sus primeros actos fue la encíclica Acerbo nimis, verdadera carta de enseñanza religiosa de la infancia. Esta práctica religiosa, extendida por entonces en Francia, también se desarrolló en las escuelas de Tarragona, Cambrils, Tortosa y Barcelona, donde en esos años se conoce la existencia de la Congregación de la Santísima Virgen para los niños de 8 a 12 años. ${ }^{40} \mathrm{De}$ la misma manera en el Colegio Condal de Barcelona estaba establecida la congregación de la Inmaculada y de San Juan Bautista de La Salle con un reglamento de las secciones catequísticas del centro, señalando la organización interna, las diferentes secciones y sus protectores (Ángel de la Guarda, Estanislao de Kotska, Sagrado Corazón de Jesús y San Luis Gonzaga). Asimismo se señala que el catecismo será el indicado por la diócesis y que la enseñanza será llevada a cabo en la lengua regional, indicando curiosamente que los alumnos que desconozcan la lengua catalana formarán una división aparte y serán instruidos en lengua española. ${ }^{41}$ No obstante, en 1902 una orden gubernamental señala la obligatoriedad de utilizar únicamente catecismos en castellano, contra la práctica existente hasta entonces de utilizarlos escritos en las lenguas vernáculas (euskara, catalán o gallego). ${ }^{42}$

Siguiendo esta misma línea de defensa del catecismo, el Instituto de los Hermanos de las Escuelas Cristianas en 1938 publicará una circular ${ }^{43}$ indicando la acción catequística que tienen que llevar a cabo. Se trata de un extenso documento donde se defiende la vocación catequética de los Hermanos y su objetivo de cumplir con la misión catequística que le caracteriza. En este sentido, entre otras cosas, se insiste en las maneras pedagógicas de enseñar el catecismo. Un apartado que tiene especial importancia es el de la relación entre la definición de la acción católica y las labores de participación de los laicos en el apostolado y su relación con la jerarquía de la Iglesia y los deberes que supone este tipo de acción,

\footnotetext{
${ }^{40}$ Institute des Écoles Chrétiennes, «L'œuvre des Catéchistes volontaires et son organisation dans quelques écoles d'Espagne», Bulletin des Écoles Chrétiennes, 4 (1908): 193-203.

${ }^{41}$ Artículo 15. ${ }^{\circ}$ del reglamento. Institute des Écoles Chrétiennes, «L'œuvre des Catéchistes volontaires et son organisation dans quelques écoles d'Espagne», 200.

42 Paulí Dávila, «El modelo histórico de alfabetización en Euskal Herriak», en Lengua, escuela y cultura: el proceso de alfabetización en Euskal Herria, siglos XIX y XX, ed. Paulí Dávila (Leioa: Universidad del País Vasco, 1995), 17-44.

${ }^{43}$ Institut des Frères des Écoles Chrétiennes, L'action catéchistique du frère des écoles chrétiennes, Circular n. ${ }^{\circ} 300$ (Lembecq Lez Hall (Bélgica), Maison St. Joseph, 1938).
} 
además de la importancia de estar asociado en alguna de las congregaciones marianas.

Tal es la importancia de la catequesis dentro de las escuelas de La Salle que, con el transcurrir del tiempo, se llegarán a celebrar certámenes catequísticos a fin de demostrar el grado de conocimiento del Catecismo por parte del alumnado. En este sentido los certámenes catequísticos constituyeron otra actividad dentro de la vida religiosa de los alumnos. Así, en 1950 se celebró el primero de ellos en el colegio de Los Ángeles de Donostia. La selección del Buen Pastor de Legazpi consiguió el primer puesto con el consiguiente trofeo donado por el Hermano Visitador, pero la trayectoria de estos certámenes fue relativamente corta, pues desde mediados de los 60 no hay más noticias de su existencia.

Pero en el caso de Gipuzkoa estos certámenes adquirieron un carácter más relevante al celebrarse exámenes de religión interprovinciales en los que el Colegio de Santa Ana de Ordizia participó repetidamente durante los años 1951, 1955 y 1956. Sin embargo, ya desde 1939 comenzaron a celebrarse exámenes de catecismo en el centro de Zumarraga, obteniendo los alumnos en ese año los tres primeros premios en los realizados por la parroquia, celebrados con motivo de la Primera Comunión de los niños. Otros años, este concurso de catecismo se celebraba entre clases del mismo colegio. No obstante, también la parroquia se sentía responsable de la formación catequística de los niños, con lo cual surgiría algún roce con el Cura Párroco, como ocurrió en 1942.44

Finalmente, estos concursos catequísticos tuvieron mayor continuidad en Andoain, sobre todo uniéndose, a partir de 1966, con la Unión de Catequistas de Jesús Crucificado y de María Inmaculada. Todavía en 1979 se menciona esta labor, aunque esta vez con referencia a la parroquia:

los domingos se reúnen en el colegio en dos tandas, los de euzkera (sic) y los de habla castellana. Finalizado el acto se reúnen para asistir al acto eucarístico. Lo bueno de todo ello es que los alumnos que acuden son de nuestro colegio, de las Escuelas Nacionales y de la Ikastola. ${ }^{45}$

\footnotetext{
${ }^{44}$ Supplément à l'Historique pour l'année 1942.

45 Suplemento al Histórico para el año 1979.
} 
Siguiendo en esta tónica, aunque con nuevas formas, a partir de 1989 en las enseñanzas medias se proponen expresiones de Fe que van tomando cuerpo con el establecimiento de una celebración una vez por trimestre, creando un grupo de profundización de la Fe entre los alumnos procedentes de bachillerato, de los alumnos mayores de Electrónica, o estableciendo cada mes un día especial de oración, o a partir de las convivencias.

\section{De los ejercicios espirituales a las convivencias}

Otras actividades permanentes en la mayoría de los colegios religiosos eran los ejercicios espirituales, convivencias, adoraciones nocturnas y peregrinaciones varias, además de la participación de los alumnos en congregaciones como la del Santísimo Niño Jesús, la Cruzada Eucarística o la Congregación Mariana. Los ejercicios espirituales, dirigidos a los alumnos de mayor edad, tuvieron desde sus inicios una mayor permanencia, pues ya en 1938, en el colegio San Luis de Herrera, a los dos meses de empezar las clases, se llevaron a cabo. En el año 1953 se trascribieron las preguntas que se hacían en los mismos, siguiendo el dictado de tradición jesuítica: «¿Razón de mi existencia?... ¿Qué rumbo sigo?... ¿Debo rectificar algo?... ». ${ }^{46}$

Los años 1963, 1964 y 1965 estuvieron destinados a la celebración de los ejercicios espirituales en la escuela profesional de Irún, en los que tomaban parte los alumnos de $2 .^{\circ}$ y $3 .^{\circ}$ de Oficialía. Fueron unos ejercicios orientados a estudiar su elección de estado y vida espiritual. Como recompensa, en el año 1966 los alumnos tuvieron la posibilidad de acudir al Convento de la Estrella, sito en San Asensio (La Rioja) a realizar los ejercicios, ${ }^{47}$ reconociéndose también el buen funcionamiento de la Unión de Catequistas, que albergaba a una docena de muchachos de 15 y 16 años y agradecer la regularidad con la que se había venido manifestando la Congregación del Santísimo Niño Jesús. También el colegio Loinaz de Beasain se caracterizó por la celebración de retiros y de ejercicios espirituales desde sus inicios hasta fechas recientes, aunque a partir de los años setenta van a ir cobrando fuerza la celebración de las Semanas

\footnotetext{
46 Suplemento al Histórico para el año 1953.

47 Koldo Iñarra y otros, Irungo La Salle, 50 urte behar berrietan zabalik (Irun: La Salle, 2004$), 53$.
} 
Vocacionales o las Semanas Lasalianas, los grupos de reflexión cristiana, las convivencias o las Jornadas de Justicia y Paz.

Los lugares elegidos para la celebración de los ejercicios espirituales variaban en función de la cercanía a monasterios o centros de peregrinación emblemáticos del País Vasco, para el caso de La Salle Donostia en Burlada; y para el Santiago Apóstol de Bilbao en Bujedo, Seminario de Vitoria o Santuario de Loyola. Lo mismo ocurría en el Colegio Bonanova de Barcelona, donde el lugar de celebración de estos ejercicios era Manresa, ciudad emblemática para los jesuitas. Así, por ejemplo, en los ejercicios espirituales de La Salle Donostia celebrados en 1956-57 se llevaron a cabo dos tandas, formadas por grupos de alumnos de preuniversitario y quinto de comercio que se dirigieron a las nuevas instalaciones de Burlada. Tal era la importancia que se le concedía a este evento que incluso la memoria escolar de ese año se abre con un artículo titulado «Yo estuve en Burlada». ${ }^{48}$

Las impresiones recogidas en estos ejercicios espirituales quedan patentes a través de las narraciones que se publican en las memorias escolares del centro tanto por parte de alumnos como por parte de los directores de los ejercicios. Así, el alumno Antonio María Aguirre, después de su regreso de Loyola, relata la experiencia de santificación que supusieron dichos ejercicios y su significado para la misión de apostolado, señalando el beneficio de los ejercicios espirituales como un "grandioso don del cielo».99 Además, estos ejercicios parece que cumplían una doble función, pues también servían "para pedir luz a Dios respecto a la elección de estado y ¿Por qué no? Para elegir una carrera que llene nuestras aspiraciones y nos sirva para nuestro fin supremo». ${ }^{50}$ Afirmaciones similares se recogen en las memorias escolares del Colegio Bonanova de Barcelona en la misma época. ${ }^{51}$ Por lo que respecta a la impresión causada por el director de ejercicios, D. José M. Cirarda, años más tarde obispo, pone

\footnotetext{
${ }^{48}$ Colegio La Salle San Sebastián, Memoria escolar del Colegio La Salle San Sebastián, curso 1956-57 (San Sebastián: Colegio La Salle San Sebastián).

${ }_{49}$ Colegio Santiago Apóstol, Memoria escolar del Santiago Apóstol, curso 1941-42 (Bilbao: Colegio Santiago Apóstol, 1942), 83.

${ }^{50}$ Colegio Santiago Apóstol, Memoria escolar del Santiago Apóstol, curso 1941-42 (Bilbao: Colegio Santiago Apóstol, 1942), 81.

51 Colegio de Nuestra Señora de la Bonanova. Memoria Escolar 1943-1944 (Barcelona: Colegio de Nuestra Señora de la Bonanova, 1944).
} 
de relieve el significado de estos ejercicios al convertir la Iglesia en un colegio de cátedra de hogar y al remarcar la colaboración entre los Hermanos de La Salle y los padres de los alumnos, encaminados todos ellos a la mejor formación humana y cristiana. ${ }^{52}$

Hasta 1980 todavía se continúa hablando de «ejercicios espirituales» en la mayoría de la documentación consultada, aunque ya se comienza a utilizar otra expresión como "días de convivencia», como ocurre, por ejemplo, desde 1978 en el Colegio San José de Zarautz. No obstante, el colegio San Luis de Herrera, a partir de 1983 cambia la denominación por la de «ejercicios de convivencias del alumnado». Desconocemos si se trataba de la misma actividad, pero lo cierto es que desde esa fecha la palabra que más se va a ir usando es la de "convivencia» con diferentes grupos y durará prácticamente hasta la actualidad, aunque en 1997 se reseñe la celebración de unos «ejercicios espirituales» durante la Semana Santa.

\section{Asociaciones religiosas u Obras Complementarias de Apostolado}

Como es conocido, a finales del siglo XIX y en el primer tercio del xx, se produce una toma de posición por parte de la Iglesia, encaminada a lograr la unidad entre los diferentes estamentos, organismos e instituciones. Para ello se creó una red de asociaciones católicas que pudiesen expandir el apostolado, a partir de círculos de obreros, asociaciones, etc. ante el proceso de secularización y, en algunos casos, de anticlericalismo que se produjo en Europa y también en España. Las innovaciones que supusieron en aquella época los medios de comunicación de masas también ayudaron a que la Iglesia pusiese en valor esta nueva situación para introducir algunas novedades en la vida espiritual de los católicos españoles. Los Papas Pío X (1903-1914) y Benedicto XV (1914-1922) fueron, de alguna manera, los artífices que permitieron revitalizar la vida religiosa y espiritual a través de la catequesis, la centralidad de la Eucaristía, la devoción mariana o la formación del clero, etc. ${ }^{53}$ En este sentido la unión de los obispos era un medio de afrontar este periodo crítico. ${ }^{54}$

\footnotetext{
52 Colegio Santiago Apóstol, Memoria escolar del Santiago Apóstol, curso 1954-55 (Bilbao: Colegio Santiago Apóstol, 1955), 38-39.

${ }^{53}$ Federico Requena, «Vida religiosa y espiritual en la España de principios del siglo XX». Anuario de Historia de la Iglesia, XI (2002): 44.

${ }^{54}$ Dávila, «Las órdenes y congregaciones».
} 
Las congregaciones y órdenes religiosas fueron las que lideraron las instituciones de formación y apostolado en la España de esa época ${ }^{55} \mathrm{y}$, sobre todo, la escuela fue el medio ideal para llevar a cabo esta misión. Hemos de tener en cuenta que la presencia de comunidades francesas fue muy importante para propiciar este tipo de actividades. ${ }^{56}$ Los medios para difundir la nueva visión de la Iglesia se sustentaban en dos factores: 1) la difusión de una teología espiritual, sobre todo procedente de Francia y que utilizaba como medio un conjunto de libros y revistas y 2) las congregaciones religiosas como agentes impulsores de esta nueva espiritualidad. En este sentido, además de las diferentes asociaciones de laicos católicos, también otro tipo de cofradías pretendían impulsar una nueva devoción a la Virgen María o el Sagrado Corazón.

Dentro del ámbito escolar, los colegios de La Salle, pero con una dimensión mucho más amplia en cuanto que implicaba actividades parroquiales, las obras de apostolado que obtuvieron mayor desarrollo y presencia fueron la Archicofradía del Santísimo Niño Jesús, la Congregación Mariana, la Cruzada Eucarística y la Acción Católica.

\section{Archicofradía del Santísimo Niño Jesús}

La Archicofradía del Santísimo Niño Jesús es la obra de apostolado que mayor permanencia tuvo en las escuelas y colegios de La Salle. Esta asociación obtuvo del Papa Pío X el grado de Archicofradía el 15 de octubre de $1909 .{ }^{57}$ Era una asociación que estaba radicada en la casa central de los Hermanos de La Salle de Belén. Este documento pontificio da un desarrollo inesperado a lo expresado en el Capítulo General de 1905 en el que se había mostrado la devoción tradicional por el Niño Jesús. Su objetivo principal era el de obtener del cielo sus socorros, tanto en las escuelas como fuera de ellas, respetando los deberes de la Santa Madre Iglesia, a fin de no perder la fe. ${ }^{58}$ Continuando en esta misma línea, el Bulletin de $1923^{59}$

\footnotetext{
55 Requena, «Vida religiosa y espiritual».

56 Requena, «Vida religiosa y espiritual».

${ }^{57}$ Institut des Frères des Écoles Chrétiennes, Archiconfréries du Très Saint Enfant Jésus, Circular del Superior de los Hermanos de la Escuelas Cristianas n. 167 de 15 de agosto (Lembecq Lez Hall (Bélgica): Maison St. Joseph, 1910).

58 Institut des Frères des Écoles Chrétiennes, Archiconfréries du Très Saint Enfant Jésus.

59 Institute des Écoles Chrétiennes, « La dévotion au Saint Enfant Jésus dans l'Institute des Frères des écoles Chrétiennes», Bulletin des Écoles Chretiennes, 3 (1923) : 1-10.
} 
recuerda la devoción al Santo Niño Jesús por parte del Instituto. Para ello se remarca la presencia del Niño Jesús en los noviciados. En este sentido la archicofradía se preocupa, sobre todo, de desarrollar y asegurar la vida cristiana de la escuela, recibiendo diversas indulgencias por parte del Papa Pío X. En la documentación sobre los distintos centros en España ya aparecen referencia a esta asociación misma en los años 20 del siglo Xx. Una muestra del éxito que alcanzó esta archicofradía es que a partir de 1929 publicaba su propia revista titulada Vida y Luz. ${ }^{60}$

La Archicofradía es «una asociación de niños buenos que se proponen imitar las virtudes de su divino modelo el Santísimo Niño Jesús». ${ }^{61}$ Los fines de esta asociación eran los recogidos en el documento pontificio señalado. Así los objetivos generales eran a) Impetrar del dulcísimo Niño Jesús que en todas las casas de educación tenga Dios el primer puesto de los estudios; b) Que tanto maestros como discípulos gocen de libertad en todas partes para observar las leyes de Nuestra Santa Madre Iglesia; y c) Que los niños cristianos no tengan que verse precisados a frecuentar las escuelas en donde se desconoce a Dios y donde se verían expuestos a perder la fe. Los objetivos particulares de la Congregación eran: a) Estimular a los niños a la práctica de la virtud, el amor al estudio y al trabajo; b) Procurar que trabajen simultáneamente en adquirir la virtud y la ciencia, para llegar a ser hombres de bien y de provecho para sí y para sus prójimos; y c) Hacer mejores a los demás niños dándoles buenos ejemplos y con la saludable influencia que en todo momento ejercen los buenos Congregantes. ${ }^{62}$

\footnotetext{
${ }^{60}$ La revista Vida y Luz era el órgano de la Archicofradía del Santísimo Niño Jesús y de la Cruzada Eucarística. El número uno se publicaba en 1929 y la redacción y administración estaba en Griñón, Madrid. Esta revista es continuación de El Eco de Belén y El Cruzado, órgano de la archicofradía y de la Cruzada respectivamente. Se publica mensualmente, excepto los meses de julio y agosto. En la mayoría de los números aparece la estrella con el «Signum Fidei» en la cabecera, lema reconocible de La Salle. Se pueden establecer cuatro etapas: 1) formada por los antecedentes ya citados (1918-1928) y publicada en Bugedo; 2) 1929-1944, publicada bajo el subtítulo de Revista Ilustrada, indicando que se trata del «Órgano de la Archicofradía del Santísimo Niño Jesús y de la Cruzada Eucarística»; 3) 1945-1955, se subtitula Revista escolar ilustrada; y 4) octubre de 1965 a diciembre de 1992, subtitulada Revista infantil y juvenil.

${ }^{61}$ Vida y Luz (época segunda), VI (53, 73 y 74), (1934). En esta revista existía un apartado especial denominado «La Sección de la Archicofradía». En este año, y a lo largo de unos cuantos números de la revista, se publican los reglamentos de esta asociación. El año de publicación y revitalización de esta revista y de sus asociaciones no debe pasar desapercibido en un contexto donde estaba en vigor la Ley de Congregaciones religiosas en las que se limitaban las actividades de las mismas.
}

${ }^{62}$ Vida y Luz (época segunda), VI (53, 73 y 74), (1934). 
Las condiciones que se requerían para ingresar en la Congregación eran: a) Solicitarlo por escrito del encargado de la Congregación; b) Cumplir bien todos los deberes de la Religión y del escolar cristiano; y c) Ser admitido en la Junta general extraordinaria por mayoría de votos; y los motivos de expulsión podían ser: a) La negligencia notable en el cumplimiento de los deberes religiosos y escolares; b) La mala conducta en la Iglesia, en la escuela o en la calle; y c) El incumplimiento habitual de los puntos esenciales del Reglamento de la Congregación. ${ }^{63}$

Existe un par de asuntos interesantes a destacar: por una parte, la elección de sus miembros se realizaba entre los alumnos de los cursos elemental y medio, que ingresaban en la Congregación de María Inmaculada al pasar al curso superior; por otra, la simultaneidad de las Congregaciones del Santísimo Niño Jesús, de María Inmaculada y de la Cruzada Eucarística, en un mismo centro. Según entienden los redactores de la revista Vida y Luz:

Nos parece que estas tres Asociaciones, lejos de perjudicarse mutuamente, pueden muy bien coexistir en un mismo Centro. Desde luego, si la Cruzada Eucarística no está establecida en el Colegio, creemos que debe dársele preferencia, no porque en sí tenga más importancia que las demás, sino porque la experiencia demuestra que es más eficaz para hacer adelantar en virtud y producir frutos de santidad. Por lo tanto, en este caso las reuniones de las Congregaciones podrían tenerse una vez al mes; por ejemplo, el día 25 para la del Niño Jesús y el primer sábado de mes para la de la Santísima Virgen. Los Cruzados se reunirán los jueves o los domingos, según circunstancias de cada localidad. Los mismos Congregantes pueden formar parte de la Cruzada Eucarística. Sin embargo, como esta asociación tiene un carácter, como quien dice, varonil y guerrero, es preferible no admitir en ella de golpe a todos los Congregantes, sino que convendrá hacer una selección de entre los más valientes y más decididos a pisotear o vencer el respeto humano. ${ }^{64}$

\footnotetext{
${ }^{63}$ Vida y Luz (época segunda), VI (54), (1934): 105-106.

${ }^{64}$ Vida y Luz (época segunda), VI (54), (1934): 105-106.
} 
La pertenencia a este tipo de asociaciones suponía una serie de sacrificios que, si se superaban, daban lugar a la obtención de algunos premios, distintivos y reconocimientos. Así el rellenar la denominada «hoja de sacrificios» y entregarla en la administración de la Archicofradía suponía el reconocimiento contable en el denominado «tesoro espiritual» de la asociación, que se publicaba cada mes en la revista Vida y Luz. A modo de ejemplo podemos ver el tipo de sacrificios que realizaban los congregantes y que eran puntualmente registrados por cada uno de los centros donde existía la asociación.

Tabla 1. Tesoro espiritual de los Archicofrades del Niño Jesús y de los Cruzados Eucarísticos

\begin{tabular}{|l|r|l|r|}
\hline Confesiones & 3.956 & Jaculatorias & 602.398 \\
\hline Comuniones & 21.639 & $\begin{array}{l}\text { Actos de virtud (obediencia, } \\
\text { paciencia, humildad, caridad, etc.) }\end{array}$ & 137.716 \\
\hline Comuniones espirituales & 104.947 & Horas de silencio & 70.805 \\
\hline Misas oídas & 23.176 & Lecturas piadosas & 30.179 \\
\hline Visitas al Santísimo & 68.037 & $\begin{array}{l}\text { Obras de Apostolado (buena } \\
\text { prensa, visita a los ancianos } \\
\text { enfermos) }\end{array}$ & 49.666 \\
\hline Decenas de Rosario & 150.250 & Viacrucris & $\mathbf{1 . 4 1 6 . 9 2 5}$ \\
\hline Mortificaciones & 147.479 & Limosnas & 2.255 \\
\hline TOTAL DE BUENAS OBRAS & &
\end{tabular}

Fuente: Vida y Luz, VI (54), (1934): 105-106.

A medida que se iban incorporando colegios la estadística irá aumentando llegando en algún año a más de tres millones de sacrificios realizados por los congregantes de 41 centros. ${ }^{65}$ Como puede observarse el tipo de sacrificios era de orden diferente y amplio, en cuanto abordaba desde comportamientos religiosos o morales, a prácticas de caridad y propia mortificación. Un estudio de este tipo de tasación en las prácticas a lo largo del tiempo nos arrojaría información sobre la prevalencia de determinados sacrificios religiosos, el sacrificio y la voluntariedad.

65 Vida y Luz, 84 (1953): 84. 


\section{Congregación Mariana}

Una de las primeras asociaciones de apostolado que comenzó a funcionar en los Colegios de La Salle, siguiendo la tradición mariana, fue la Congregación de María Inmaculada y San Juan Bautista de La Salle, de la cual ya encontramos noticias sobre su existencia en la memoria escolar de 1912 del Colegio Nuestra Señora de la Bonanova de Barcelona, donde se recoge la lista de «señoritos congregantes y aspirantes» de dicha congregación. Asimismo, en la primera memoria que publica el Santiago Apóstol en 1931, ya recoge documentación gráfica sobre su existencia, continuando a lo largo de todos los años con las informaciones correspondientes a dicha congregación, como ocurre en 1943, donde se recoge que 160 alumnos forman los cuadros de la acción católica y los 95 tarsicios y 234 cruzados que «ponen bajo la solicitud de la Virgen Inmaculada el fuego purísimo del amor eucarístico».66 Por supuesto, en la información gráfica que se da de estos grupos aparecen las diferentes secciones de la Cruzada Eucarística, así como de los aspirantes a la JACE (Juventud de Acción Católica Española). En dichas fotografías aparecen los estandartes, escapularios y otros signos de pertenencia a dichas asociaciones. Imágenes similares se repiten en las memorias de los años posteriores.

La mención a esta Congregación se hace, a veces, de una manera general, incluyendo las actividades de la Archicofradía del Niño Jesús y la Cruzada Eucarística, con ello se da a entender que bajo el paraguas de Congregación Mariana se acogen estas diferentes secciones que se distinguen por la edad de los congregantes. En ellas, además de describir las actividades que llevan a cabo se pone de relieve la organización de excursiones y otras actividades lúdicas que «saben ceder el paso naturalmente a una piedad ardiente cuando se trata de postrarse a los pies de nuestra reina inmaculada». ${ }^{67}$

En el País Vasco el Colegio de Santa María de Vitoria y el Colegio Católico Santa María de San Sebastián, ${ }^{68}$ regidos por los Marianistas,

\footnotetext{
${ }^{66}$ Colegio Santiago Apóstol, Memoria escolar del Santiago Apóstol, curso 1942-43 (Bilbao: Colegio Santiago Apóstol, 1943), 91.

${ }^{67}$ Colegio Santiago Apóstol, Memoria escolar del Santiago Apóstol, curso 1951-52 (Bilbao: Colegio Santiago Apóstol, 1936), 76.

68 Federico Ríos y Fermín Gastaminza, 100 años de presencia marianista en San Sebastián (18871987) (Madrid: SM, 1988).
} 
también pusieron en marcha este tipo de asociaciones, agrupadas bajo la denominación común de "La Congregación de María Inmaculada». En su organización se contaba con una Junta General y tres secciones, la sección de Nuestra Señora del Pilar, la Sección de San José y la Sección de los Ángeles Custodios, según su edad. ${ }^{69}$ De la misma manera, conocemos la existencia de la Congregación Mariana desde 1872 en el Colegio San José de Valencia, regido por los Jesuitas. ${ }^{70}$

\section{Cruzada Eucarística}

Otra de las asociaciones más asentadas en los colegios es la Cruzada Eucarística, que era la sección especial destinada a niños y adolescentes del Apostolado de la Oración. El objetivo de esta asociación era

prepararlos para una perfecta vida cristiana y formarlos en el espíritu apostólico, mediante el conocimiento y amor de Nuestro Señor Jesucristo y, principalmente, mediante una íntima unión de vida y de sacrificio con Él, que por nosotros se inmola continuamente en la Santa Eucaristía. ${ }^{71}$

Los medios para poder desarrollar las prácticas de la Cruzada Eucarística, eran los mismos que los del Apostolado de la Oración: 1) Ofrecimiento diario; 2) Sacrificio de la Misa y Sagrada Comunión; 3) Devoción al Corazón Sacratísimo de Jesús; 4) Devoción a la Virgen María; 5) Obediencia filial al Sumo Pontífice: Obediencia al Papa, pero también deben reverenciar y amar al propio Obispo, orar por él y, de acuerdo con sus mandatos, colaborar con la Acción Católica en la diócesis y en la parroquia; y 6) Este programa de la Cruzada Eucarística se contiene en sus cuatro consignas: Rezar, comulgar, sacrificarse, hacer postulado. ${ }^{72}$ La importancia de esta actividad era tan relevante que incluso se llegó a producir material fotográ-

${ }^{69}$ Colegio Católico Santa María, Ecos del Colegio, curso 1941-42 (San Sebastián: Colegio Católico Santa María, 1942), 16. Esta memoria escolar es la primera que se publica después de la guerra civil y es continuación de una publicación anterior. En los siguientes números se recoge información sobre este tipo de asociaciones bajo el epígrafe de «Congregación Mariana», al igual que lo hace sobre la Acción Católica.

${ }^{70}$ Llull Martí, Jesuitas y pedagogía, 87 y 528 y ss.

71 «Normas para dirigir la cruzada eucarística del apostolado de la oración», El Mensajero del Corazón de Jesús, 836, (1958): 8.

72 «Normas para dirigir la cruzada eucarística del apostolado de la oración», 12. 
fico y filminas para su proyección por las escuelas, publicándose un libro que servía de apoyo a la labor del Director o propagandista de la Cruzada. ${ }^{73}$

La organización dependía del Moderador Supremo de la Cruzada Eucarística que era el Propósito de la Compañía de Jesús. Estaba organizada por diócesis y los directores diocesanos y locales dependían de los Ordinarios del lugar. Generalmente, la Cruzada comprendía a niños y adolescentes entre los seis y los catorce años; a no ser que hubiera razones para que los jóvenes perseverasen en ella hasta los dieciséis, y aún los dieciocho años, o que los niños fueran admitidos antes de los seis. Para el correcto funcionamiento de la Cruzada había tres secciones, según la edad: sección para párvulos de seis a ocho años; sección para niños de nueve a once años, y sección de preadolescentes desde los doce a los quince. La sección que requería más atención era la segunda, en la que ya reciben el nombre de Cruzados, a los que se les debe enseñar: 1) Que cada día hagan con más perfección su ofrecimiento al Corazón de Jesús y acomoden toda su vida y las obligaciones de su propio estado al espíritu de este ofrecimiento; 2) Que penetren más profundamente en el conocimiento del Santo Sacrificio de la Misa, y se acostumbren a participar en ella de un modo más perfecto, y que siempre que asistan al Sacrificio Eucarístico procuren, en cuanto sea posible, recibir la Sagrada Comunión o, al menos, que cada semana se acerquen a la Sagrada Mesa; y 3) Que se vayan preparando, según su edad y aptitudes, a ejercer el apostolado. Los directores deben encaminar a los niños, y sobre todo a los adolescentes, a la participación activa en la Acción Católica. ${ }^{74}$

El mismo sentido tiene la Cruzada Eucarística en el caso de los Marianistas de San Sebastián, donde una de las actividades más importantes eran las procesiones que realizaban por las calles de la ciudad vestidos como auténticos cruzados con lanzas y estandartes. De esta manera, los cruzados, eran «los futuros Congregantes, Jóvenes, Hombres de Acción Católica, Adoradores nocturnos y Miembros de las Conferencias de San Vicente». ${ }^{75}$

\footnotetext{
${ }^{73}$ José Julio Martínez S. J., Escenas de la Cruzada Eucarística (Bilbao: El Mensajero del Corazón de Jesús, 1961).

${ }^{74}$ Martínez S.J., Escenas de la Cruzada Eucarística, 27-28.

${ }^{75}$ Colegio Católico Santa María, Ecos del Colegio, curso 1952-53 (San Sebastián: Colegio Católico Santa María, 1953), 15.
} 
Los Tarsicios era otra asociación que tuvo implantación en algunos colegios, aunque a veces de forma intermitente. El objetivo de esta asociación era

fomentar el espíritu religioso entre sus asociados y proporcionar a la vez un medio más para conservarse dentro del camino recto en el tiempo de estancia en el Colegio y a la salida de él con las enseñanzas aprendidas. También es un fin de esta Asociación el formar Adoradores Nocturnos, puesto que los Tarsicios son como un grado elemental de la Adoración Nocturna. El medio de que se vale es también esencial: el inculcar el amor a la Sagrada Eucaristía con la Comunión mensual y las prácticas que a ella van anejas. ${ }^{76}$

Un ejemplo de este tipo de prácticas, y del funcionamiento de las asociaciones, lo podemos encontrar en la escuela de Legazpi, donde desde el 15 de mayo de 1944 funcionaba la Congregación de la Inmaculada y de San Juan Bautista de La Salle para fomentar la piedad entre sus mejores alumnos. Juntamente se había constituido un turno de Tarsicios que "celebraba mensualmente su vigilia y estaba animado del mejor deseo de alabar al Santísimo Sacramento del Altar». ${ }^{77}$

A ella acudían muchos alumnos, como se puede ver en la siguiente tabla:

Tabla 2. Legazpi. Obras Complementarias y Vida Cristiana

de la Escuela (1944-1968)

\begin{tabular}{|c|c|c|c|}
\hline Año & $\begin{array}{c}\text { Archicofradía } \\
\text { del Niño Jesús }\end{array}$ & $\begin{array}{c}\text { Congregación de la } \\
\text { Virgen María }\end{array}$ & $\begin{array}{c}\text { Cruzada } \\
\text { Eucarística }\end{array}$ \\
\hline 1944 & & 72 & \\
\hline 1945 & & 82 & \\
\hline 1946 & 60 & 98 & \\
\hline 1947 & 60 & 90 & 120 \\
\hline 1948 & 70 & 70 & 140 \\
\hline 1949 & 70 & 70 & \\
\hline
\end{tabular}

${ }^{76}$ Colegio Santiago Apóstol, Memoria escolar del Santiago Apóstol, curso 1935-36 (Bilbao: Colegio Santiago Apóstol, 1936), 91.

${ }_{77}$ Supplément à l'Historique pour l'année 1944 (AHSLB). 


\begin{tabular}{|c|c|c|c|}
\hline Año & $\begin{array}{c}\text { Archicofradía } \\
\text { del Niño Jesús }\end{array}$ & $\begin{array}{c}\text { Congregación de la } \\
\text { Virgen María }\end{array}$ & $\begin{array}{c}\text { Cruzada } \\
\text { Eucarística }\end{array}$ \\
\hline 1950 & 60 & 65 & 120 \\
\hline 1951 & 60 & 65 & 120 \\
\hline 1952 & 60 & 68 & 110 \\
\hline 1953 & 75 & 60 & \\
\hline 1954 & 85 & 70 & \\
\hline 1955 & 85 & 74 & \\
\hline 1956 & 87 & 70 & \\
\hline 1957 & 90 & 65 & \\
\hline 1958 & 150 & 80 & 110 \\
\hline 1959 & 199 & 40 & 98 \\
\hline 1960 & 108 & 40 & 85 \\
\hline 1961 & 116 & 100 & \\
\hline 1962 & 56 & 72 & \\
\hline 1963 & 112 & 100 & \\
\hline 1964 & 104 & 98 & \\
\hline 1965 & 118 & 105 & \\
\hline 1966 & 158 & 104 & \\
\hline 1967 & 158 & 86 & \\
\hline 1968 & 180 & & \\
\hline
\end{tabular}

Este mismo tipo de asociaciones funcionó en escuelas como la de Los Ángeles de Donostia, que ya desde 1938 estaba en plena pujanza para mantener la piedad y formación cristiana entre los alumnos. También en Usurbil se llevaban a cabo las novenas mensuales de un nutrido grupo de la Congregación del Santísimo Niño Jesús. En el colegio San Luis de Herrera se hallaban establecidas en la Escuela dos Asociaciones Piadosas:

la Congregación del Santísimo Niño Jesús, para los alumnos pequeños, que agrupa bajo su bandera a 87 benjamines, y para los colegiales mayores, la Sección de Tarsicios, cuyos 60 militantes encienden sus corazones en ardores eucarísticos en la fervorosa intimidad de sus vigilias mensuales. Entre los componentes de estos dos grupos de selectos todos los años distingue el Señor con la vocación religiosa o sacerdotal a varios alumnos, que su 
predilección ha escogido para seguirle de cerca. Este año fueron tres los que respondieron generosa y valientemente al llamamiento divino. ${ }^{78}$

Estas obras ya estaban establecidas en la etapa anterior de este colegio, pero comienzan a ponerse en funcionamiento en 1941, sobre todo la Obra Eucarística de los Tarsicios con 38 alumnos que «juraron la bandera, prometiendo a Jesús Sacramentado hacer todos los meses la hora de guardia como pajes leales e incondicionales» ${ }^{79}$ En 1962 la mayoría de los niños estaban involucrados a la Congregación del Niño Jesús, a la Cruzada Eucarística o a la Congregación Mariana. Desconocemos hasta cuando estuvieron en funcionamiento estas asociaciones, pues los datos obtenidos tan sólo llegan hasta 1967.

Lo mismo ocurre en el Colegio San José de Zarauz, de manera que las comuniones de los primeros viernes de mes y en todas las fiestas principales era un recurso habitual que complementaba la explicación diaria del catecismo y los concursos catequísticos. La Asociación Eucarística de los Tarsicios llevaba a cabo todos los últimos domingos de mes su «vigilia» con toda fidelidad y fervor, «mientras las mundanas gentes corren a los cines y paseos». ${ }^{80}$ Los Tarsicios fueron los encargados de llevar la Bandera el día del funeral de uno de los niños fallecidos. Por otra parte, en el denominado «Domingo de Tarsicios» se dice textualmente: «son los Hermanos los que lo animan, sostienen y encauzan, y no los Srs. curas». Cuando se saca la foto de todo el personal del Colegio, los Tarsicios lo hacen en grupo aparte ${ }^{81} \mathrm{La}$ importancia de la Primera Comunión queda expresada de esta manera: «Siete angelitos hacen la comunión», y todos coincidían en que «así había que celebrar el día más feliz de la vida». ${ }^{82}$ La comunión no sólo era patrimonio de las asociaciones apostólicas, sino que está presente en cualquier festividad que se llevase a cabo, como se aprecia, sobre todo, en las décadas de los años cuarenta y cincuenta.

\footnotetext{
${ }^{78}$ Libro de Actas del Colegio San Luis. AHSLB, Caja 869-Carpeta 25.

${ }^{79}$ Libro de Actas del Colegio San Luis. AHSLB, Caja 869-Carpeta 25.

${ }^{80}$ Crónica de la Casa de Zarauz, 1938 (AHSLB).

${ }^{81}$ Crónica de la Casa de Zarauz, 1942 (AHSLB).

82 Crónica de la Casa de Zarauz, 1944 (AHSLB).
} 
De manera tardía, en los centros de Beasain y Zumarraga se implantó este tipo de asociaciones, después de que el Hermano Visitador insistiese en 1949 en que los Hermanos «traten de organizar dentro del colegio la Archicrofadía del Niño Jesús y el Centro interno de Acción Católica», ${ }^{83}$ pero no será hasta 1959 cuando el propio Visitador informe de que se ha organizado la Archicrofadía del Niño Jesús. En el colegio de Zumarraga, también en 1962 se aconseja que el director del colegio procure «que se ponga prontamente en marcha las asociaciones piadosas que ayuden a promover la generosidad y piedad de los alumnos mejor dispuestos». ${ }^{84}$

Tenemos que, a la vista de la información que poseemos, este tipo de asociaciones tiene su época dorada en las décadas de los cincuenta y sesenta, cuando los niños podían participar en diversas congregaciones simultáneamente o bien continuar en las mismas, según su edad. No obstante, todavía en la década de los 80, se aprecia como en la Escuela Profesional de Irún se lanza un proyecto de educación en la fe con dos grupos de catecumenado con vistas a la confirmación. En la mayoría de centros de La Salle estas actividades se irán reconvirtiendo en comunidades cristianas, diversificando su acción y tomando conciencia en actividades de solidaridad y campañas de concienciación con el Tercer Mundo.

\section{La Acción Católica y las obras de apostolado}

Muchos de los objetivos que perseguían las asociaciones de apostolado que hemos citado, dedicadas a los jóvenes y adolescentes, coincidían con los principios que regían la Acción Católica, sobre todo en su rama juvenil, que desde los años veinte comenzara a funcionar como Juventud Católica Española (JCE) para crear un sistema basado en actividades de cada centro. La JCE, no tenía como objetivo específico la acción política, sino, más bien, la formación religiosa de masas juveniles católicas. Durante la Segunda República su actividad fue más política debido a las circunstancias anticlericales que se vivían. Las cuatro ramas de la Acción Católica Española (ACE) según sus Bases de 1932 se integraron con el nombre de Juventud de Acción Católica (JAC). ${ }^{85}$

\footnotetext{
${ }^{83}$ Suplemento al Histórico para el año 1949 (AHSLB).

${ }^{84}$ Suplemento al Histórico para el año 1962 (AHSLB).

${ }^{85}$ Chiaki Watanabe, «La Juventud Católica Española: Orígenes y primer desarrollo», Espacio, tiempo y forma. Historia contemporánea, 8 (1995): 131-140, o Pedro Escartín Celaya «Apuntes para la Historia
} 
En los centros de La Salle, al igual que en la mayoría de los colegios religiosos, la presencia de Acción Católica ya era conocida en los años inmediatos a la finalización de la guerra. Así, en la información facilitada en el Bulletin 108 de 1947 sobre Acción Católica en España, se observa que las asociaciones de antiguos alumnos de los centros Condal, Bonanova y Josepets mantenían equipos de catequistas voluntarios con una amplia actividad. ${ }^{86}$ De la misma manera en el curso 1940-41, en el Colegio Santiago Apóstol de Bilbao, se informa que desde 1938 la JACE (Juventud de Acción Católica Española) está organizada en «Círculos de estudios». También el Colegio Católico de Santa María de los Marianistas en San Sebastián organizó la Acción Católica en 1942 en el centro bajo el nombre de Acción Católica de San Pablo. ${ }^{87}$ Igualmente en el distrito de Madrid en 1946 existían círculos de antiguos alumnos que desarrollaban obras de apostolado. La situación en España es muy parecida a la existente en países como Canadá, Italia o Francia.

La actividad de la Acción Católica en el Santiago Apóstol de Bilbao consistía, sobre todo, en la acción cultural y propagandística, a partir de "comentarios sobre el evangelio, conferencias misionales, de información social católica, etc». ${ }^{88}$ Además de estas actividades, los domingos, cuarenta catequistas vulgarizaban «los rudimentos del Catecismo a 300 niños pobres de la parroquia de San Francisco». ${ }^{89}$ Con buen criterio, además de esta ayuda espiritual encaminada a preparar a los niños para la Primera Comunión, les ayudaban económicamente a comprarse el traje de comunión, no con dinero propio, sino «organizando con este fin una rifa y una velada benéfica». Durante los años siguientes esta actividad de la JACE continuará, como se registra en las memorias escolares correspondientes. Los cambios que se van a producir durante el franquismo dentro de Acción Católica, debido al papel preponderante de la Acción

\footnotetext{
de la Acción Católica en España», Acción Católica General. http://www.accioncatolicageneral.es/ index.php?option=com_docman\&task=doc_download\&gid=481\&Itemid=27 (consultado el 15-22016).

${ }^{86}$ Institute des Écoles Chrétiennes, «Action catholique», Bulletin des écoles Chrétiennes, 108 (1947): 49.

87 Colegio Católico Santa María, Ecos del Colegio, curso 1941-42 (San Sebastián: Colegio Católico Santa María, 1942), 22-24.

${ }_{88}$ Colegio Santiago Apóstol, Memoria escolar del Santiago Apóstol, curso 1940-41 (Bilbao: Colegio Santiago Apóstol, 1941), 22.

${ }^{89}$ Colegio Santiago Apóstol, Memoria escolar del Santiago Apóstol, curso 1940-41, 22.
} 
Católica especializada, conllevarán una mayor politización a partir de la década de los años sesenta. ${ }^{90}$

Una buena descripción de este conjunto de actividades y asociaciones que, en general, funcionaban en los colegios de La Salle, lo podemos encontrar la memoria del curso 1949-50 del Colegio Nuestra Señora de la Bonanova de Barcelona. Las asociaciones religiosas estaban incluidas dentro del programa de educación cristiano propiciado por los Hermanos de La Salle, complementándose unas con otras. ${ }^{91}$ Así, la Acción Católica, fundada en el colegio en 1940, se organizaba de tal manera, que creaba un ambiente de actividad espiritual militante y proselitista, saturando de sobrenatural el reglamento y la actividad escolar. En este sentido, se aprecia una organización dirigida por el Hermano Director de la Acción Católica y una serie de cargos relacionados con la acción diocesana de jóvenes y el propio centro. La Congregación Mariana era la más preciada joya de la Acción Católica, pues incrementaba con sus actos específicos la vida de piedad. En ese momento contaba con unos 160 congregantes. En cambio la Congregación del Santísimo Niño Jesús que contaba con 95 miembros, era la que iniciaba a los futuros Aspirante y Jóvenes de la Acción Católica en la vida de intensa piedad que les dispondrá luego a las tareas del apostolado. A lo largo del curso se celebraban diversas festividades religiosas lúdicas y deportivas, que servían para dejar huella en los alumnos. Por otra parte, todo este tipo de militancia en asociaciones de apostolado era un buen semillero para vocaciones religiosas. ${ }^{92}$

\section{CONCLUSIONES}

En España y en el País Vasco en el primer tercio del siglo xx y posteriormente en el franquismo se aprecia un creciente aumento de la religiosidad y de la unidad de la Iglesia frente a algunas posturas anticlericales. En este contexto las escuelas y colegios privados religiosos se van a transformar en un espacio de apostolado. Además de la presencia de la religión como asignatura obligatoria y del conjunto de celebraciones litúrgicas llevadas a cabo en los centros escolares, se creó un conjunto de

\footnotetext{
${ }^{90}$ Montero, «Los movimientos juveniles de Acción Católica».

${ }_{91}$ Colegio de Nuestra Señora de la Bonanova, Memoria Escolar 1949-1950 (Barcelona: Colegio de Nuestra Señora de la Bonanova, 1950), 46 y ss.

92 Dávila y Naya, «La enseñanza privada religiosa».
} 
asociaciones de apostolado para los niños y adolescentes, con diferente denominación, que adquirieron una relevancia fundamental para propagar la fe, a través de dos focos de atención: la eucaristía y la devoción mariana.

Este conjunto de asociaciones se conforma como una red de dependencia entre el alumnado, las parroquias y el centro escolar, con el objetivo de posibilitar la permanencia de las prácticas eucarísticas y de la devoción mariana a través de los años. Existe, por tanto, una transición del alumnado que va desde la Archicofradía del Santísimo Niño Jesús, para los niños de menor edad, hasta la JACE para los mayores. De esta manera se pasaba de la catequesis para celebrar la Primera Comunión hasta la Acción Católica en un proceso continuado, donde los alumnos se involucraban en diversas prácticas y actividades, tanto escolares como extraescolares. El periodo de mayor efervescencia de estas actividades coincide con los años cuarenta al sesenta del siglo XX, en pleno franquismo, que es la época dorada de las órdenes y congregaciones religiosas dedicadas a la enseñanza.

Esta actividad de apostolado vinculaba a los alumnos a las propias asociaciones, pero también a la convivencia de grupos de laicos y seglares en actividades religiosas y, en algún caso, políticas, lo cual permitía prolongar la actividad religiosa más allá del espacio escolar. El objetivo último de todo este tipo de asociacionismo religioso, junto con las celebraciones eucarísticas y los ejercicios espirituales, era involucrar a los niños, adolescentes y jóvenes en una experiencia de fe que asegurase la defensa de la religión católica dentro de un encuadramiento organizativo en el que estaban implicados la jerarquía eclesiástica (desde los obispos hasta los curas), las órdenes y congregaciones religiosas dedicadas a la enseñanza y las propias familias del alumnado para compartir un proyecto de unidad católica. 


\section{Notas sobre los autores:}

Paulí Dávila Balsera es Catedrático de Historia de la Educación de la Universidad del País Vasco/Euskal Herriko Unibertsitatea. Su línea de investigación está centrada en la historia de la educación en el País Vasco sobre la cual ha publicado diversos libros y artículos científicos relativos a la formación profesional, a los procesos de alfabetización, la política educativa, el magisterio, el currículum vasco, patrimonio histórico-educativo, etc. Es el investigador principal del Grupo de Estudios Históricos y Comparados en Educación - Garaian, reconocido por el Gobierno Vasco y el director del Museo de la Educación de la Universidad del País Vasco.

Luis María Naya Garmendia es Profesor Titular del Departamento de Teoría e Historia de la Educación de la Universidad del País Vasco/Euskal Herriko Unibertsitatea, donde imparte Educación Comparada. Ha publicado y coordinado diversos libros y artículos sobre el derecho a la educación y los derechos de los niños, historia de la educación y patrimonio histórico-educativo. Es miembro del Grupo de Estudios Históricos y Comparados en Educación - Garaian, reconocido por el Gobierno Vasco, coordinador de la Unidad de Formación e Investigación «Educación, Cultura y Sociedad» y miembro del consejo de dirección del Museo de la Educación de la Universidad del País Vasco.

Hilario Murua CARTón en la actualidad es profesor Adjunto de la UPV/ EHU impartiendo docencia en la Facultad de Educación, Filosofía y Antropología de Donostia-San Sebastián. Diplomado en Magisterio (1992) y licenciado en Pedagogía (2000), obtuvo el doctorado con la clasificación de «Sobresaliente Cum Laude» en marzo de 2006, presentando la tesis «La Enseñanza Primaria y el Magisterio en Gipuzkoa, 1936-1975». En su trayectoria académica y profesional ha participado en numerosos proyectos de investigación bajo la dirección de los catedráticos Paulí Dávila Balsera y Félix Etxeberria Balerdi. Asimismo ha escrito entre otros libros La Formación Profesional en Euskal Herria: evolución y agentes promotores (2016) o Bajo el signo de la educación: 100 años de La Salle en Gipuzkoa, los manuales de la asignatura «Teoría e Historia de la Educación» en euskara y castellano, y ha publicado diversos artículos en revistas especializadas en educación. Además es miembro del Grupo Consolidado de Investigación Garaian y de la Unidad de Formación e Investigación «Educación, Cultura y Sociedad». 
